\title{
CONTRIBUIÇÃO DA PESQUISA CIENTÍFICA BRASILEIRA NO DESENVOLVIMENTO DE ALGUMAS FRUTÍFERAS DE CLIMA SUBTROPICAL ${ }^{1}$
}

\author{
FERNANDO MENDES PEREIRA ${ }^{2}$ \& RYOSUKE KAVATI ${ }^{3}$
}

RESUMO - Quando se considera aptidão climática, as plantas frutíferas são classificadas em: tropicais, subtropicais e temperadas. Esta tradicional classificação, por muito tempo, mostrou-se bastante efetiva. Os mais atuais conhecimentos dos centros de origens de diferentes espécies, os avanços tecnológicos na condução dos pomares e na conservação dos frutos e especialmente o melhoramento genético criaram condições excepcionais para o cultivo de espécies tropicais e temperadas em clima subtropical.

No presente trabalho foram selecionadas as culturas da atemoieira, do caquizeiro, da figueira e da goiabeira com base não apenas na importância nacional e regional, mas também pelas diferentes contribuições que a pesquisa científica ofereceu a estas frutíferas.

Atemoieira - dentre as espécies frutíferas exploradas em larga escala, talvez seja a de mais recente introdução de cultivo no Brasil, iniciado em meados da década de 1980. Diversas técnicas de cultivo foram desenvolvidas, como porta-enxertos mais adequados para cada região, podas de formação e produção, polinização artificial, manejo de pragas e doenças, e diversas outras tecnologias que permitiram rápida expansão da cultura em diversas regiões do País. Embora o importante papel das Universidades, Institutos de Pesquisas e Extensão seja inquestionável, foi fundamental a contribuição dos produtores pioneiros que iniciaram a busca de soluções para os problemas surgidos, indicando as necessidades para intervenções da pesquisa.

Caquizeiro - a produção brasileira de caqui (IBGE - 2009), de 171.555 t, é obtida em uma área de 8.770 ha e representa um valor de 146,67 milhões de reais. São Estados maiores produtores São Paulo (111.646 t), Rio Grande do Sul, Paraná e Rio de Janeiro). As principais cultivares em produção são: Rama Forte, Giombo e Fuyu, que são comercializados prioritariamente no mercado interno.

Figueira - a produção brasileira de figos vem mantendo-se com pequenas variações nos anos de 2000, atingindo 24.146 t em 2009 (IBGE - IBRAF), sendo os Estados do Rio Grande do Sul e São Paulo, os maiores produtores . No Estado de São Paulo, o cultivo concentra-se quase que exclusivamente na região de Campinas, sendo a produção de 9.469 t em 2010 (IEA). Os frutos colhidos graças à tecnologia desenvolvida é, em parte, exportada como figo de mesa (1.645 t em 2008). Fonte DECEX (MICT) IBRAF - 2010. Goiabeira - o cultivo da goiabeira no Brasil permite considerá-la atualmente como uma espécie plenamente adaptada ao clima subtropical. O desenvolvimento de variedades adaptadas e técnicas especiais de cultivo propiciaram grande expansão desta cultura no Brasil. Segundo o IBGE - IBRAF, em 2009, o Brasil produziu 297.377 t em uma área de 15.048 ha. Pernambuco, São Paulo, Brasília, Rio de Janeiro e Bahia são os principais produtores. No Estado de São Paulo, é importante destacar a produção de goiabas para mesa (50.000 t) que graças à alta qualidade dos frutos é exportado com sucesso.

Termos para indexação: Frutas, atemóia, caqui, figo e goiaba.

\section{CONTRIBUTION OF THE BRAZILIAN SCIENTIFIC RESEARCH IN THE DEVELOPMENT OF SOME FRUIT TREES OF SUBTROPICAL CLIMATE}

\begin{abstract}
Considering the climatic aptitude the fruit plants are classified in: tropical, subtropical and temperate. This traditional classification was very effective during a long period of time.

Based on more update knowledge of the origin centers of the different species, the technological advances in the fruit crops and, in the fruit conservation and specially the genetic breeding created exceptional for the cropping of tropical species and temperate in subtropical climate.

In this research were select the atemoya, persimmon, fig tree and guava crop based not only in the national and regional importance but also in the different contributions that the scientific research offered to the fruit plants.
\end{abstract}

\footnotetext{
${ }^{1}$ Palestra Sinfruit 100 - Simpósio Internacional de Fruticultura - Avanços na Fruticultura (17 a 21 Outubro)

${ }^{2}$ Prof. Titular, FCAV - Unesp, Jaboticabal. E-mail: pereira_fernando@terra.com.br

${ }^{3}$ Eng. Agr ${ }^{\circ}$. Dr., Coordenadoria de Assistência Técnica Integral. E-mail: kavati@uol.com.br
} 
Atemoya - within the fruit species exploited in a large scale may be the more recent introduction in cropping in Brazil, initiated in the 1980 decade. Several techniques of cropping were developed such as root stocks more adequate for each region, pruning, artificial pollination, pest management and disease control and several others technologies that permitted a fast expansion of the fruit crops in several country regions.

Although the remarkable contribution of the Universities, Research Institutes and Extension Agencies, was fundamental the pioneer contribution of the producers to solve the problems of the crops indicating the necessity for more research in this crop fruit.

Persimmon - the Brazilian production of persimmon (IBGE - 2009) was 171,555 tons was obtained in a area of 8,770 ha and represented a value of 146,67 real millions. The major production states in Brazil were São Paulo (111,646 tons) Rio Grande do Sul, Paraná and Rio de Janeiro. The main cultivars in production are: 'Rama Forte', 'Giombo' and 'Fuyu' which are found in the internal market.

Fig tree - the Brazilian production of fig at 2009 according to IBGE - IBRAF were 24,146 tons being the major production states in Brazil the Rio Grande do Sul and São Paulo. At São Paulo the fig production is concentrate in the Campinas region, being a production of 9,469 tons in 2010 (IEA). The harvested fruit due to developed technology is export as fresh fruits (1,645 tons at 2008). Source: DECEX (MCT) IBRAF - 2010. Guava crop - the guava crop in Brazil is adapted to a subtropical climate. This crop in Brazil had a great expansion due to the development of cultivars adapted to the climate and special techniques of cultivation. According to IBGE - IBRAF at 2009 Brazil produced 297,377 tons in a area of 15,048 ha. The major productions areas are located at Pernambuco, São Paulo, Brasilia, Rio de Janeiro and Bahia. In São Paulo states were produced more guava for fresh consumption due to the high quality of fruit harvested $(50,000$ tons).

Index terms: fruits, atemoya, persimmon, fig tree, guava crop.

\section{INTRODUÇÃO}

Quando se considera aptidão climática, as plantas frutíferas são classificadas em: tropicais, subtropicais e temperadas. Esta tradicional classificação, por muito tempo, mostrou-se bastante efetiva.

As frutíferas tropicais são aquelas cujos centros de origem são as zonas tropicais do planeta, que se apresentam sempre cobertas de vegetação. As frutíferas de clima temperado têm como característica básica a perda completa de folhas por ocasião do inverno. As frutíferas de clima subtropical, evidentemente, são as cultivadas nas zonas subtropicais do globo terrestre que, mesmo ocorrendo em regiões de climas mais amenos, não perdem suas folhas no inverno. Entre estas, as plantas cítricas destacam-se pela grande importância econômica no cenário mundial. Outras espécies, como a nespereira e a nogueira-macadâmia, destacam-se como típicas plantas de clima subtropical.

Essa atual classificação mostrou-se por muito tempo bastante efetiva. Entretanto, os atuais conhecimentos sobre os centros de origem de diferentes espécies, os avanços tecnológicos na condução dos pomares e especialmente os trabalhos realizados na área do melhoramento genético criaram excepcionais condições para o cultivo de espécies tropicais e temperadas em regiões de clima subtropical.

Atualmente, a quase totalidade das espécies de plantas frutíferas tropicais e de clima temperado são economicamente cultivadas nas zonas de clima subtropical. Como exemplos de espécies tropicais cultivadas em zonas de clima subtropical, podem-se citar, entre muitas outras, a goiabeira e o cajueiro.

Entre as plantas de clima temperado, são exemplos marcantes pessegueiro, videira, figueira, ameixeira e caquizeiro.

No presente trabalho, foram selecionadas as culturas de atemoieira, do caquizeiro, da figueira e da goiabeira, com base não apenas na importância econômica nacional e regional, mas também pelas diferentes formas de contribuição que a pesquisa científica ofereceu a essas fruteiras.

\section{Atemoieira - Annona cherimola x Annona squamosa}

A atemoia, um híbrido interespecífico entre uma espécie originária de clima tropical de altitude (Annona cherimola Mill.) e outra de clima tropical seco (Annona squamosa L.), é constituída de inúmeras variedades, algumas comportandose melhor sob condições de clima mais parecidas com as de origem de uma das espécies parentais, podendo, portanto, ser cultivadas sob as mais variadas condições climáticas. Embora atualmente haja uma predominância da exploração em condições de clima subtropical, através do cultivo da variedade Thompson, a cultura também é feita sob condições do semiárido Nordestino, principalmente com a variedade Gefner.

Dentre as inúmeras espécies frutíferas que tiveram uma expansão significativa na área 
cultivada nos últimos anos, em função do interesse econômico por elas despertado, a atemoia destacase pelo rápido crescimento da área cultivada e pelo seu estabelecimento no mercado brasileiro. Considerando que se trata de uma fruta recentemente lançada no mercado, uma vez que passou a ser frequentemente ofertada, pelo menos no mercado de São Paulo, apenas em meados da década de 1990, e apenas com 15 anos, o volume comercializado é bastante significativo, sendo que, na maior central de abastecimento do País, a CEAGESP, são atualmente comercializadas cerca de duas mil toneladas anuais. Esta quantidade comercializada pode ser comparada com a comercialização da fruta-do-conde ou pinha - A. squamosa, outra fruta exótica, mas que já está presente neste mercado desde a década de 1960, atingindo uma média de comercialização, nos últimos anos, de cerca de três mil toneladas anuais (WATANABE, 2011), conforme pode ser verificado pelos dados apresentados no Quadro 1.

QUADRO 1 - Quantidades em toneladas de atemoia e de fruta-do-conde, comercializadas através do CEAGESP, no período de 2003 a 2010. Fonte: CEAGESP.

\begin{tabular}{|c|c|c|}
\hline Anos & Atemoia - ton. & Fruta-do-conde - ton. \\
\hline 2003 & $1.097,19$ & $3.238,72$ \\
\hline 2004 & $1.296,93$ & $2.656,11$ \\
\hline 2005 & $1.718,52$ & $2.705,92$ \\
\hline 2006 & $1.880,68$ & $2.630,50$ \\
\hline 2007 & $1.837,69$ & $2.968,95$ \\
\hline 2008 & $2.123,38$ & $3.851,98$ \\
\hline 2009 & $1.969,07$ & $3.629,08$ \\
\hline 2010 & $2.046,99$ & $2.927,90$ \\
\hline
\end{tabular}

É considerada ainda uma fruta relativamente desconhecida pela maioria dos consumidores brasileiros, já que a sua comercialização basicamente ocorre em alguns centros comerciais importantes, conforme pode ser verificado pelos dados do Quadro 2 de Watanabe (2011), onde consta o volume comercializado em diversos Centrais de Abastecimento do sistema CEASA, na qual o Programa Brasileiro de Modernização do Mercado Hortigranjeiro - PROHORT, acompanha a comercialização de diversos produtos, comparando o volume comercializado de atemoia e de outras anonáceas como a fruta-do-conde e graviola $(A$. muricata L.).

QUADRO 2 - Quantidade, em toneladas, de atemoia e outras anonáceas comercializadas no ano de 2010, nas diferentes Centrais de Abastecimento que fazem parte do Programa Brasileiro de Modernização do Mercado Hortigranjeiro-PROHORT. Fonte: CEAGESP.

\begin{tabular}{|l|c|c|c|}
\hline Unidade & Atemoia & Fruta-do-conde & Graviola \\
\hline CEASA - Grande São Paulo & $2.046,99$ & $2.927,90$ & 295,63 \\
\hline CEASA - Campinas-SP & 95,49 & 53,08 & 3,16 \\
\hline CEASA - Vitória-ES & 13,38 & 219,21 & 42,08 \\
\hline CEASA - Goiânia-GO & 3,54 & 64,59 & 0,84 \\
\hline CEASA - Caratinga & 0 & 0,89 & 0 \\
\hline CEASA - Barbacena-MG & 0,46 & 0 & 0,13 \\
\hline CEASA - Gov. Valadares-MG & 0 & 0,06 & 0 \\
\hline CEASA - B. Horizonte-MG & 55,87 & 242,99 & 6,26 \\
\hline CEASA - Itajubá & 0 & 0,98 & 0 \\
\hline CEASA - Juiz de Fora-MG & 1,06 & 0,89 & 0 \\
\hline CEASA - Uberaba-MG & 0,02 & 1,13 & 0 \\
\hline CEASA - Uberlândia-MG & 3,53 & 3,24 & 0,18 \\
\hline CEASA - Varginha-MG & 0 & 10,83 & 0 \\
\hline CEASA - Foz Iguaçu-PR & 0 & 0,45 & 0 \\
\hline CEASA - Curitiba-PR & 4,94 & 6,86 & 0,73 \\
\hline CEASA - Londrina-PR & 14,23 & 2,64 & 1,70 \\
\hline CEASA - Maringá-PR & 0,45 & 0,07 & 0 \\
\hline CEASA - Gde. Rio-RJ & 72,79 & $8.857,63$ & 1,74 \\
\hline Total & $2.312,73$ & $12.392,42$ & 352,44 \\
\hline
\end{tabular}


Os dados do Quadro 2 indicam que mais de $88 \%$ das atemoias comercializadas no Brasil são feitas no Entreposto situado em São Paulo, enquanto, no mesmo período, a participação neste mercado da fruta-do-conde, que teoricamente ocupa a mesma faixa de consumo, atinge apenas $23,6 \%$ do total comercializado, indicando a potencialidade do crescimento que tem essa fruta no mercado brasileiro.

Este híbrido produzido no início do século $\mathrm{XX}$ nos EUA foi introduzido no Brasil pelo Instituto Agronômico de Campinas, na década de 1950 (TOKUNAGA, 2000). Em fins da década de 1960, já se encontravam alguns pomares instalados no Vale do Paraíba, graças à iniciativa de alguns poucos produtores que visualizavam o potencial desta fruta no mercado brasileiro. Embora nesta fase o empenho de alguns produtores e viveiristas tenha promovido alguns avanços tecnológicos marcantes, como opções de espécies para uso como porta-enxertos, a ausência de outras informações acerca de melhores métodos para a sua exploração, poucos avanços tiveram estes plantios pioneiros. A possibilidade da exploração em grande escala muito se deve aos extensionistas da CATI (Coordenadoria de Assistência Técnica Integral), órgão da Secretaria de Agricultura e Abastecimento do Estado de São
Paulo, que, baseando nos dados obtidos em áreas experimentais cultivadas no Núcleo de Produção de Mudas de São Bento do Sapucaí e em propriedades particulares no Município de Lins, passou a divulgar as melhores técnicas de cultivos e a solucionar os problemas decorrentes da exploração em grande escala (KAVATI, 1992; TOKUNAGA, 2000).

Somente em meados da década de 1990, a cultura passou a ser trabalhada pela área de pesquisa agropecuária, inicialmente nas Universidades, com a elaboração de diversas dissertações e teses como as de Kavati (1998), Savazaki (2000), Pereira (2001), Melo (2001), Pelinson (2003), Scaloppi (2003), Scaloppi (2007) e Bettiol (2008), abordando diversas áreas, como podas, polinização artificial, manejo de pragas e doenças, e outras, embora às vezes trabalhando com outras espécies, mas podendo prontamente ser estendida para a cultura de atemoia. Dos resultados práticos mais marcantes que alguns destes trabalhos proporcionaram, foi possibilitar a produção fora de época e, consequentemente, a disponibilização desta fruta no mercado durante o ano todo, o que proporciona condições para aumento significativo do consumo, além da estabilização dos preços pagos pelo consumidor, conforme pode ser verificado através dos dados apresentados no Quadro 3.

QUADRO 3 - Quantidades mensais em $\mathrm{kg}$ e preços em $\mathrm{R} \$ / \mathrm{kg}$ de atemoia no mercado atacadista de São Paulo, no período de 2008 a 2010. Fonte: CEAGESP.

\begin{tabular}{|c|c|c|c|c|c|c|}
\hline \multirow{2}{*}{ Mês } & \multicolumn{2}{|c|}{2008} & \multicolumn{2}{c|}{2009} & \multicolumn{2}{c|}{2010} \\
\cline { 2 - 7 } & $\mathrm{R} \$ / \mathrm{Kg}$ & $\mathrm{Kg}$ & $\mathrm{R} \$ / \mathrm{Kg}$ & $\mathrm{Kg}$ & $\mathrm{R} \$ / \mathrm{Kg}$ & $\mathrm{Kg}$ \\
\hline Jan. & 3,80 & 71.019 & 3,47 & 53.760 & 4,20 & 37.185 \\
\hline Fev. & 3,75 & 76.551 & 3,76 & 44.613 & 4,35 & 77.202 \\
\hline Mar. & 3,76 & 96.189 & 3,75 & 94.020 & 3,89 & 179.502 \\
\hline Abr. & 3,05 & 244.863 & 3,21 & 229.185 & 3,22 & 247.032 \\
\hline Maio & 2,94 & 343.788 & 3,24 & 336.009 & 2,63 & 314.043 \\
\hline Jun. & 2,93 & 416.595 & 3,39 & 270.795 & 3,05 & 251.622 \\
\hline Jul. & 3,55 & 257.840 & 3,58 & 248.070 & 3,21 & 298.449 \\
\hline Ago. & 3,50 & 266.406 & 3,46 & 287.649 & 3,64 & 219.597 \\
\hline Set. & 3,82 & 162.243 & 3,71 & 193.416 & 4,97 & 171.312 \\
\hline Out. & 4,42 & 86.151 & 4,25 & 97.314 & 4,83 & 100.056 \\
\hline Nov. & 4,55 & 57.264 & 4,44 & 61.200 & 5,16 & 73.725 \\
\hline Dez. & 4,34 & 44.472 & 3,81 & 53.037 & 5,04 & 77.262 \\
\hline
\end{tabular}

Em 1997, a realização do I Simpósio Brasileiro sobre Anonáceas, pela Universidade Estadual do Sudoeste da Bahia, e a publicação de Anonáceas, Produção e Mercado (SÃO JOSÉ et al., 1997) foram muito importantes para o desenvolvimento das culturas de atemoia e outras anonáceas em todo o País. Outra grande contribuição ocorreu com a publicação do livro Frutas Anonáceas: ata ou pinha, atemoia, cherimoia e graviola - Tecnologia de produção, pós-colheita e mercado (MANICA et al., 2003).

Embora haja necessidade de muitas pesquisas, ainda, para assegurar a sustentabilidade da cultura, principalmente nas áreas de fitossanidade, nutrição e pós-colheita, estes trabalhos iniciais foram fundamentais para o crescimento e o estabelecimento da atemoia no Brasil. 


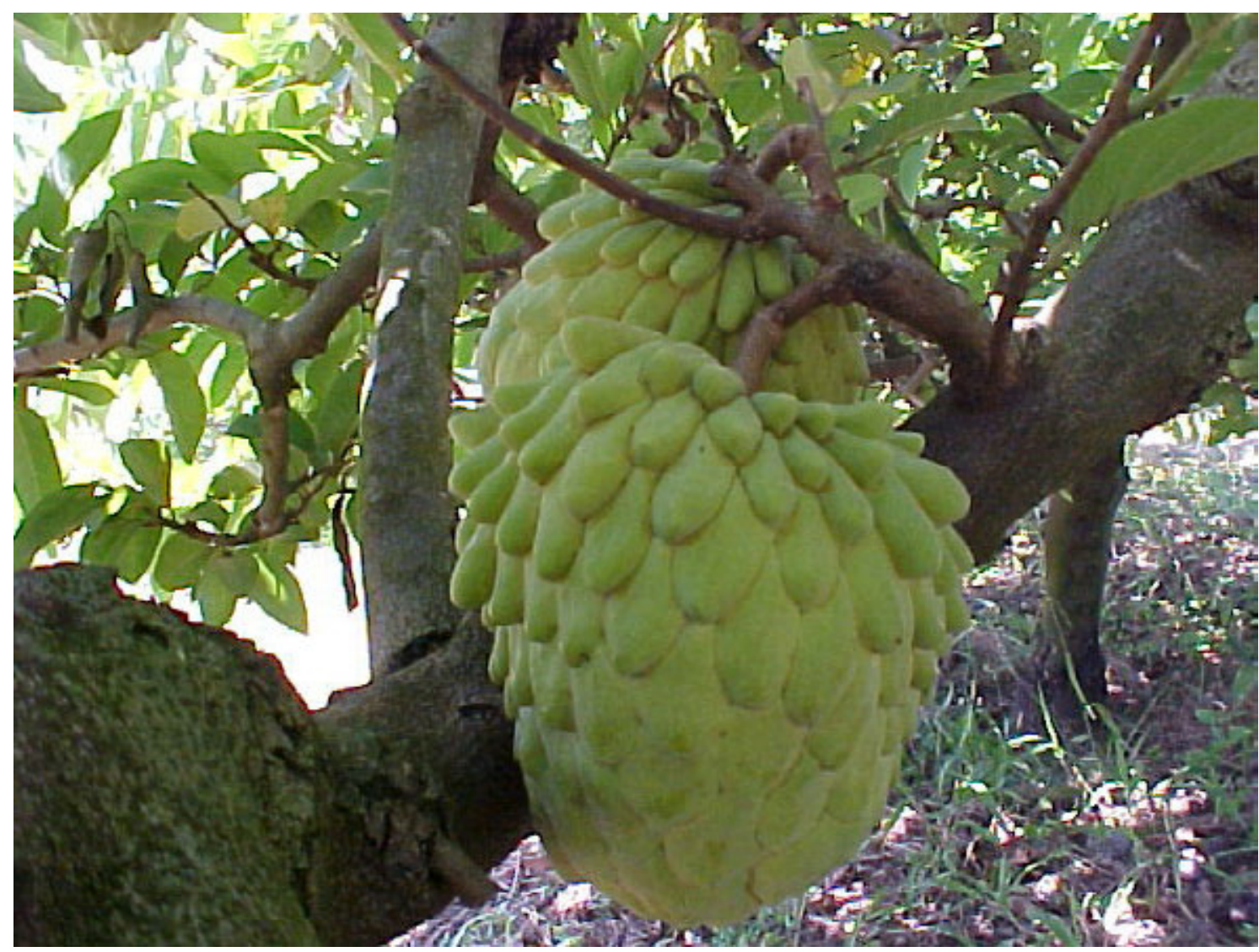

FIGURA 1 - Atemoia, cv.Thompson, bem adaptada às condições de clima subtropical.

CAQUIZEIRO - Diospirus kaki L.

O caquizeiro, pertencente ao gênero Diospyros, destaca-se na família Ebenaceae, por sua importância comercial na produção de frutos comestíveis (MARTINS;PEREIRA, 1989).

Seu centro primário de origem genética são as montanhas do China Central, havendo um centro secundário no Japão (PEREIRA et al., 2010).

Foi introduzido no Brasil por volta de 1890 por Luiz Pereira Barreto, através de sementes vindas da França. As primeiras mudas foram comercializadas em 1897 como "caquizeiro do Japão".

Posteriormente, os viveiristas João Dierberger e Francisco Marengo, encarregaram-se de introduzir e difundir pelo Brasil variedades ainda hoje existentes (SOUSA, s/d).

Entretanto, a atividade pomícola em nosso Estado só adquire feição econômica com a chegada dos fruticultores nipônicos, a partir de 1920. Estes introduziram sólidos conhecimentos de caquicultura e de muitas variedades, como Giombo e outras.

Joaquim Rama Forte leva, do bairro paulistano da Penha, para a grande cultura em Mogi das Cruzes, em 1928, o famoso caqui Rama Forte (SOUSA, s/d).
Atualmente, a produção brasileira de caqui (IBGE - 2009) é de 171.555 t produzidas em uma área de 8.770 ha e com valor aproximado de $\mathrm{R} \$$ $146.670 .000,00$

Essa produção (IEA - 2010) concentrase nos Estados de São Paulo (111.646 t), com aproximadamente $65 \%$ da produção total, Rio Grande do Sul, Paraná, Rio de Janeiro e Santa Catarina.

Os principais centros produtores paulistas são as regiões de Mogi das Cruzes, Campinas, Sorocaba, Itapeva e Itapetininga.

Embora as Universidades, os Institutos de Pesquisa e os órgãos públicos de assistência técnica tenham prestado relevantes serviços à cultura do caquizeiro, pouco efetivas contribuições foram e têm sido utilizadas pelos produtores.

Provavelmente, o pequeno interesse comercial que a cultura despertou durante largo espaço de tempo, as facilidades encontradas para a produção (graças à rusticidade e abundante produção das variedades disponíveis) e o distanciamento dos órgãos de pesquisa dos fruticultores (não por falta de uma adequada equipe de fomento) tenham 
dificultado a aplicação prática de novas tecnologias desenvolvidas.

Entre as mais relevantes contribuições ao desenvolvimento da cultura do caquizeiro no Estado de São Paulo, devem-se destacar os trabalhos relativos ao Melhoramento Genético desenvolvidos no Instituto Agronômico de Campinas.

Inicialmente, com a introdução e a implantação de lotes de observação, foram desenvolvidos cuidadosos estudos em relação ao comportamento adaptativo de várias variedades de caquizeiro. A partir de 1950, iniciou-se o trabalho de cruzamentos controlados entre as variedades mais promissoras.

Das hibridações resultantes, foram selecionadas e lançadas as cultivares 'Pomelo' (IAC 6-22), 'Rubi' (IAC 8-4), 'Kaoru' (IAC 13-6), 'Regina (IAC - 5) e, posteriormente, 'Fuyuhana' (IAC 152-7) (OJIMA e Outros, 1989).
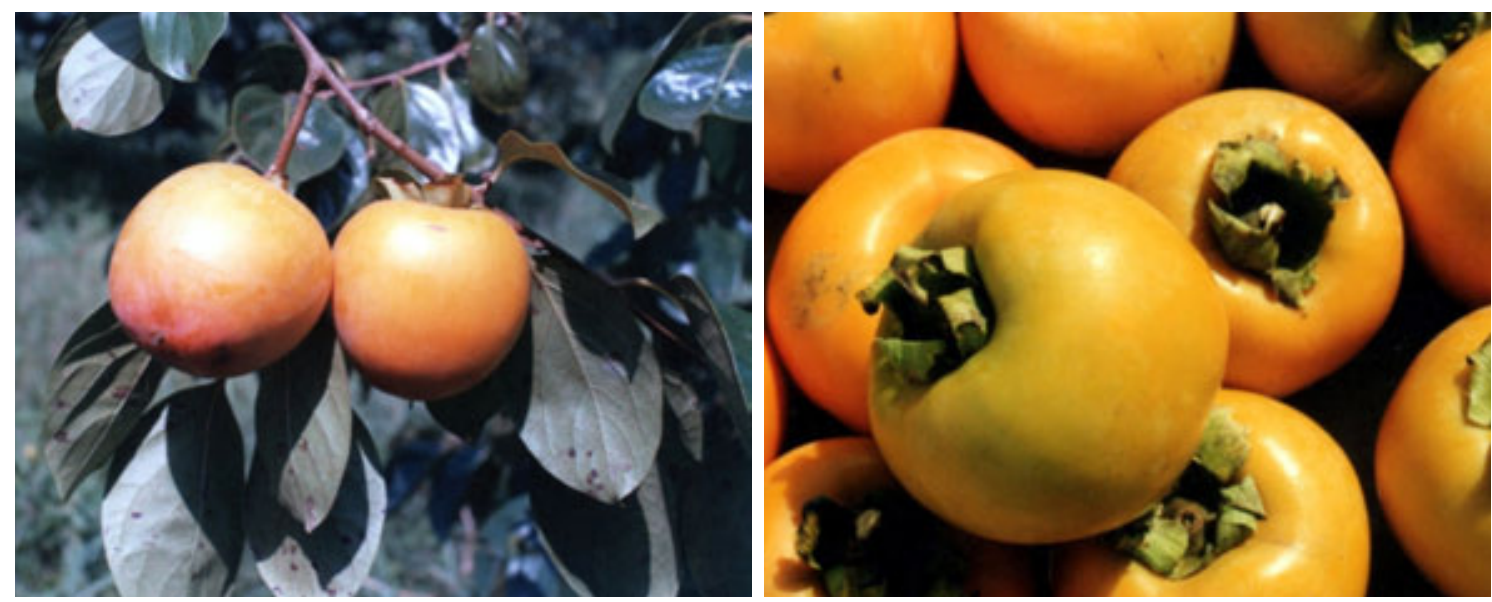

FIGURA 2 - Respectivamente, cultivares de Pomelo e Fuyuhana.

Pomelo - em que pesem as ótimas características pomológicas e produtivas desses materiais, os produtores de caqui não os utilizaram nos cultivos comerciais, preferindo seguir com as variedades Rama Forte, Taubaté e Giombo e Fuyu.

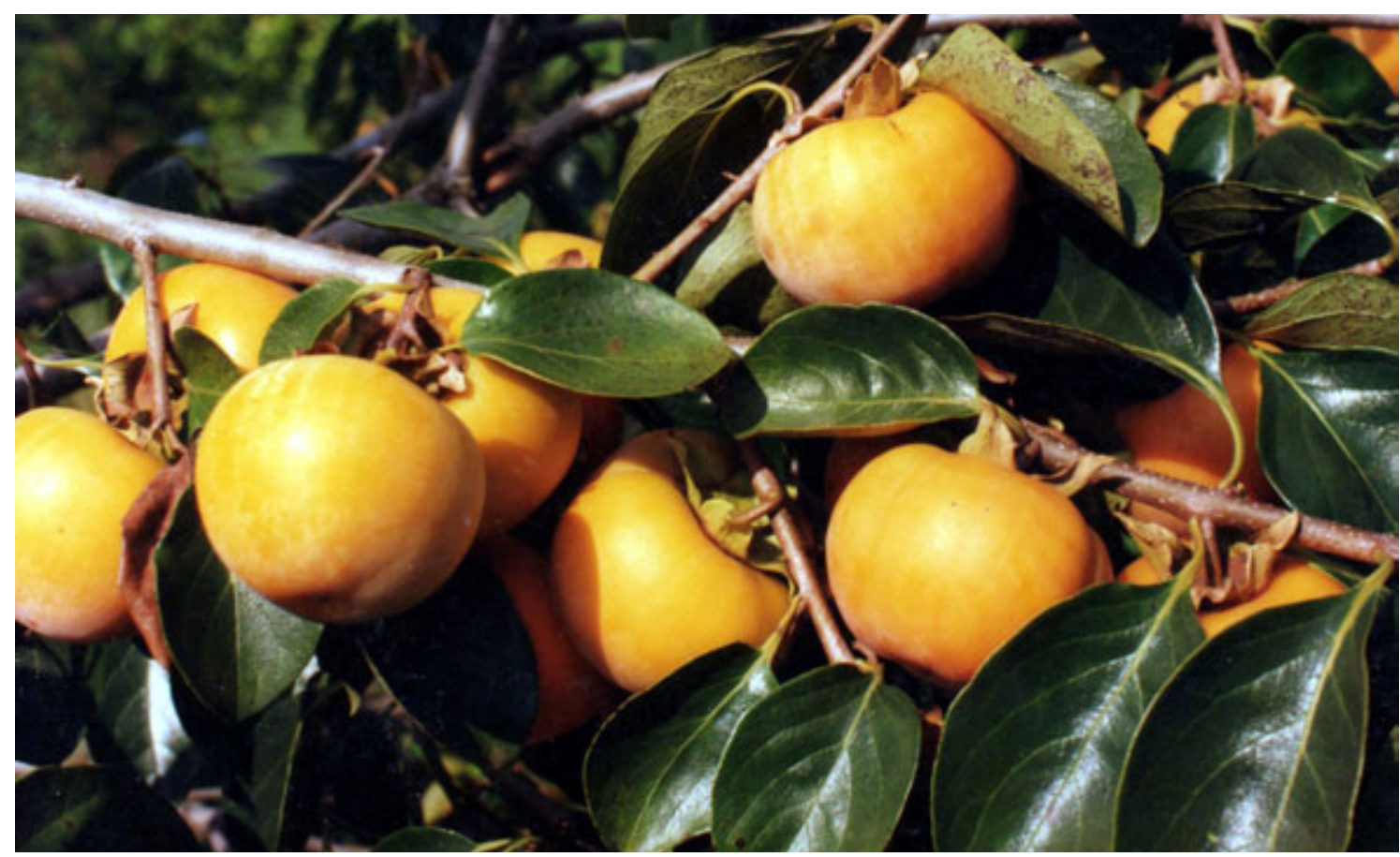

FIGURA 3 - Cultivar Rama Forte, frutos muito apreciados no mercado interno. 


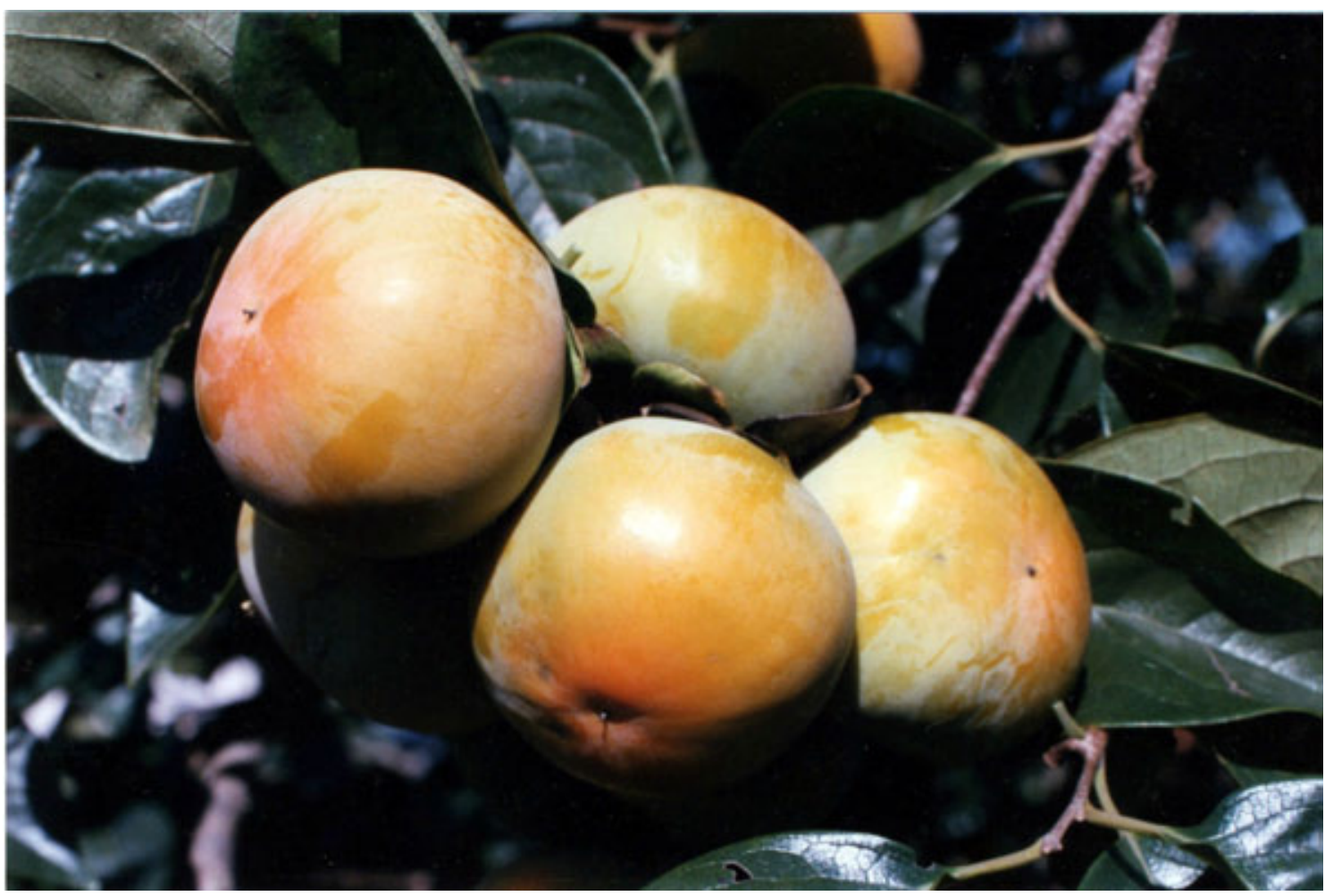

FIGURA 4 - Fuyu, a mais consagrada variedade de caqui no mundo.

Entretanto, é possível que, com a implantação de lotes comerciais, especialmente com as cultivares Pomelo e Fuyuhana nas regiões de cultivo, no futuro, esses materiais possam vir a ser economicamente explorados.

$\mathrm{Na}$ história do caquizeiro no Brasil, pode-se observar que os grandes avanços deveram-se muitas vezes a fruticultores dedicados, a viveiristas e a engenheiros agrônomos em atividades em empresas de fomento, porém o trabalho de pesquisadores e extensionistas dos órgãos públicos foi fundamental para a consolidação do cultivo de caquizeiros no Brasil.

FIGUEIRA - Ficus carica L.

A figueira, planta da família Moraceae, foi, provavelmente, cultivada pela primeira vez nas áreas férteis do sul da Arabia, onde espécies selvagens podem ainda ser vistas.

As migrações iniciais em direção ao Ocidente foram para a Ásia. No período que marcou a queda do Império Romano (fins do Século V), a figueira foi levada não apenas em torno da costa do mar Mediterrâneo, mas também através da costa Atlântica, na África e no sul da França.

Os mouros tiveram grande influência na expansão da cultura da figueira desde o norte da
África até a Espanha e Portugal.

Durante o período dos 'grandes descobrimentos', o figo difundiu-se em cultivos por todas as regiões tropicais, subtropicais e de moderado clima temperado das Américas.

No Estado de São Paulo, muito possivelmente, a figueira foi introduzida pelos participantes da primeira expedição colonizadora de Martin Afonso de Souza, no ano de 1532. Entretanto, o cultivo comercial da figueira apenas teve início em 1910, no antigo distrito de Valinhos, com a introdução, em 1901, pelo imigrante italiano Lino Buzatto, de mudas de figueira produtoras de figos roxos vindas da Itália.

A produção, ainda hoje, concentra-se no município de Valinhos, que é conhecido nacionalmente como "Capital do Figo Roxo".

\section{Contribuição Científica}

As análises dos documentos existentes sobre a figueira e seu cultivo no Estado de São Paulo, evidenciam uma constante participação dos órgãos de ensino, pesquisa e extensão na solução de problemas e no incremento de técnicas culturais e fitossanitárias que propiciaram o desenvolvimento desta frutífera. Entre os estudos mais importantes nos primórdios da cultura da figueira no Estado de São Paulo, devem 
ser destacadas as participações da ESALQ - USP e Instituto Agronômico de Campinas nas identificações e recomendações para o controle de fungos e insetos.

Foram aquelas duas instituições e, depois, o Instituto Biológico da Capital, que, recomendando as podas anuais enérgicas, destruição dos ramos podados e emprego das caldas fungicidas e inseticidas, que contribuíram para solucionar o problema da ampliação da safra, estendendo-a até maio (PIRES, 1970).

\section{Calda Bordaleza e Poda Drástica}

O uso de Calda Bordaleza e a Poda Drástica dos ramos do ano, eliminando fontes de inóculo de fungos (principalmente ferrugem) e destruição de pupas das brocas do ponteiro foram as mais destacadas contribuições.

A análise dos documentos técnicos e científicos sobre os pesquisadores e suas contribuições na área da fruticultura paulista encontra-se como pioneiro, com sua tese de doutorado "A cultura da figueira no Estado de São Paulo", no ano de 1955 (ESALQUSP), o pesquisador do Instituto Agronômico de Campinas Eng. Agro. Dr. Orlando Rigitano, cujo trabalho consagrou o sistema de poda drástica da figueira.

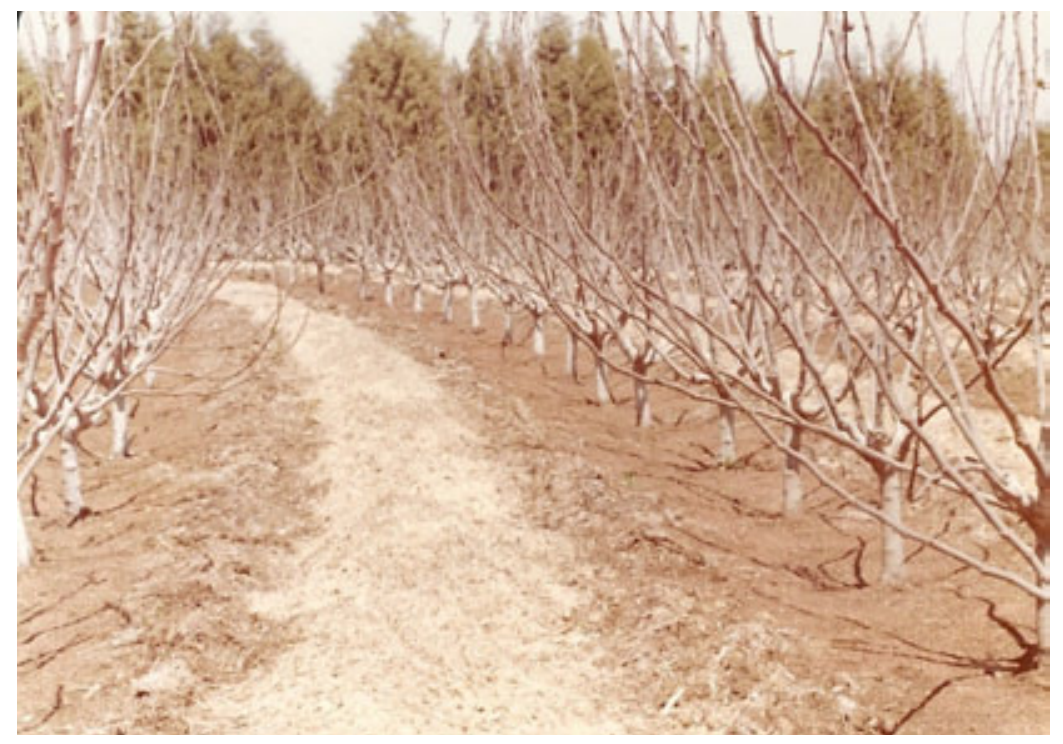

FIGURA 5 - Poda Drástica - Plantas prontas para a poda de inverno.

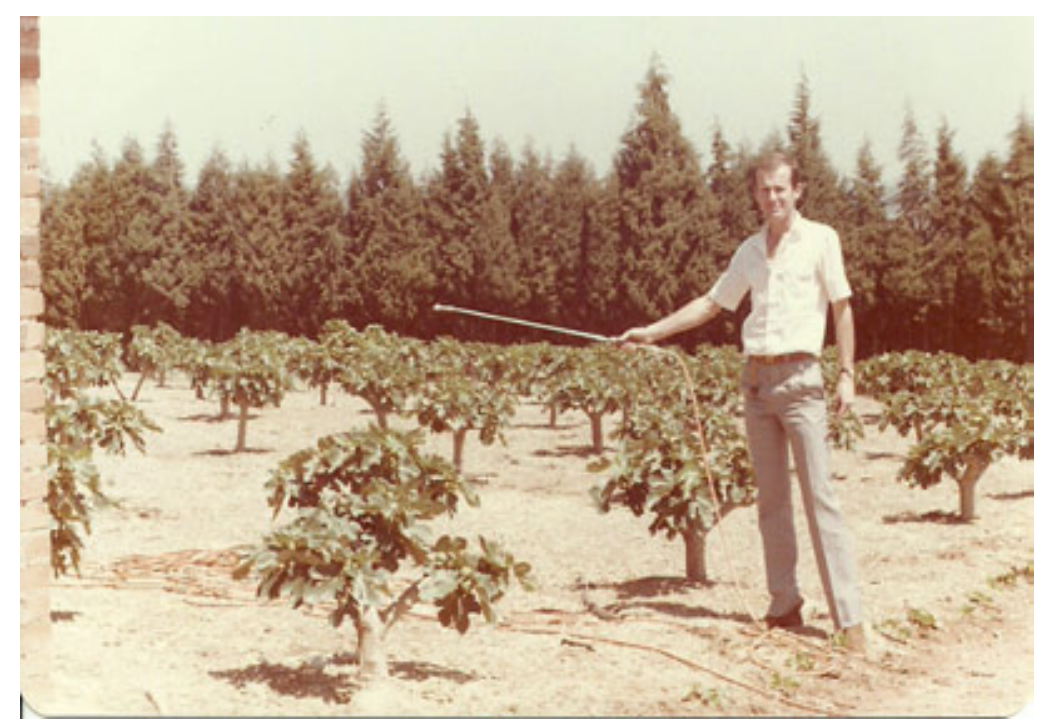

FIGURA 6 - Tratamento fitossanitário - equipamento manual 


\section{Cobertura Morta Vegetal}

Produtores incorporaram a técnica de cobertura "morta" vegetal na lavoura de figo, iniciado pelo uso de "capim-gordura" ou "meloso", quando esta planta era abundante na região, passando nos anos 70 pelo uso do bagaço de cana fornecido pelas usinas da região de Piracicaba, que, no início, era até doado aos produtores devido à abundância de produtora esteira do pró-álcool. À medida que o tempo foi passando, tornou-se quase inviável pelo custo, tanto do frete como do próprio produto, então valorizado pelas usinas na queima nas caldeiras, para gerar energia elétrica. Durante os anos 90, as indústrias de papel e celulose da região contavam com montanhas de casca de eucalipto acumuladas em seus pátios, como a Ripasa em Americana e a Champion em MogiGuaçu, que causavam problemas ambientais. Os produtores de figo da região de Valinhos e Campinas, durante mais de uma década, removeram esses resíduos e utilizaram para forrar seus figueirais. Com o fim desse material, passaram a utilizar gramínea Bachiaria decubens, que é abundante nas pastagens e terrenos em descanso na região. Com a proibição da queima da palha da cana-de-açúcar, novamente alguns produtores têm utilizados a palha recolhida nos canaviais, por métodos semelhantes à fenação (rolos) e utilizado na cobertura dos pomares de figo (Figura 3). (MAIORANO, 2010)

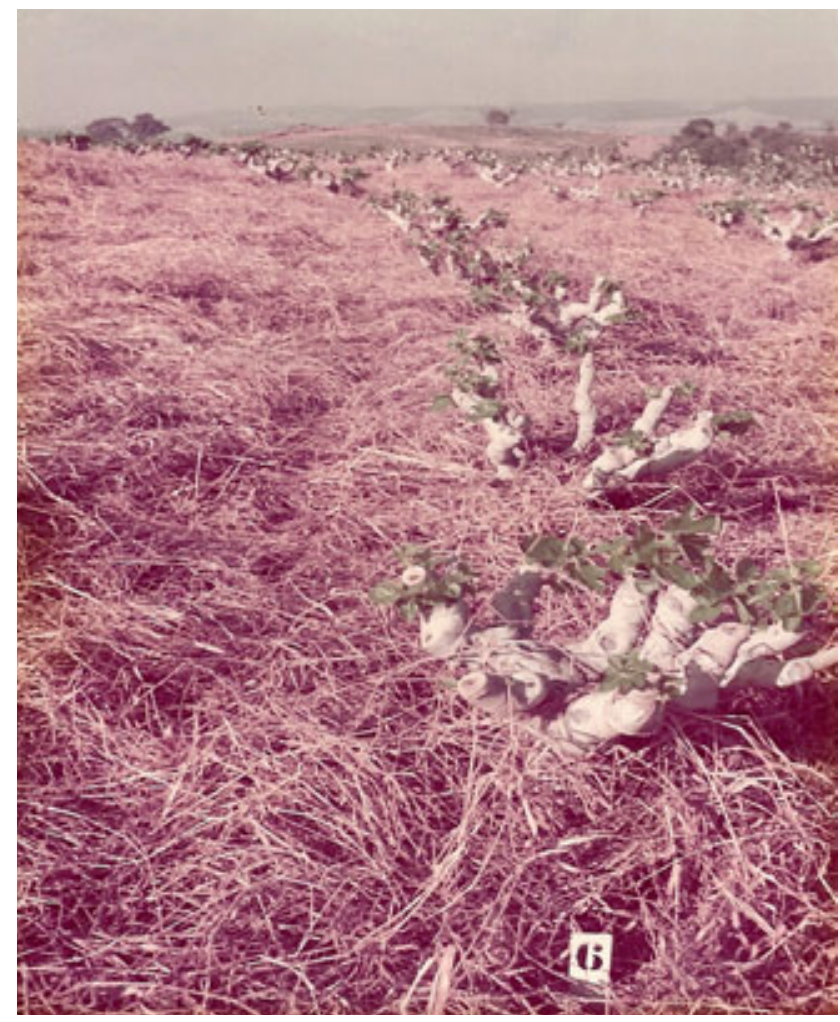

FIGURA 7 - Cobertura Morta - capim-gordura

\section{Antecipação da Maturação}

Sabe-se que, desde séculos antes de Cristo, a aplicação de uma gota de óleo no ostíolo (olho do figo) estimula o crescimento e a maturação, antecipando a colheita.

Essa operação, que utilizava grande volume de mão de obra e causava manchas nos frutos, o que diminuía seu valor comercial, não era muito recomendada. Com o surgimento de hormônios sintéticos e industriais, como o etephon, o pesquisador e professor da UNESP/Jaboticabal, Eng. Agro. Dr. Fernando Mendes Pereira, desenvolveu trabalhos com dosagens, modo e época de aplicação desse produto na antecipação do figo. Os produtores aperfeiçoaram a técnica e, hoje, é possível dizer que essa tecnologia é que tem permitido ao Brasil ser um dos maiores exportadores de figo do mundo. Podese ver no Quadro 04 que a exportação dessa fruta tem seu incremento de volume a partir dos anos 80 , quando esta pesquisa foi realizada e logo em seguida adotada pelos produtores e exportadores. $\mathrm{O}$ uso do etephon evita os períodos de "enchentes" (períodos de grande produção e preços muito baixos), assim como permite aos produtores controlar o volume de 
figos maduros a serem colhidos, de acordo com os pedidos dos exportadores, cumprindo assim com a regularidade e oferta constante da fruta ao longo de todo o período de exportação, que vai do início de dezembro até o final de maio/junho. (MAIORANO, 2010).

QUADRO 4 - Evolução da exportação de figos frescos no período de 1972/2008

\begin{tabular}{|c|c|c|c|}
\hline Ano & Valor (US\$-FOB) & Volume (kg) & Valor Unitário (US\$) \\
\hline 1974 & 3.000 & 4.000 & 0,78 \\
\hline 1979 & 66.200 & 41.000 & 1,63 \\
\hline 1984 & 394.600 & 318.000 & 1,24 \\
\hline 1989 & 703.000 & 651.000 & 1,08 \\
\hline 1994 & 921.000 & 625.000 & 1,47 \\
\hline 1999 & 1.541 .000 & 750.000 & 2,35 \\
\hline 2004 & 2.109 .142 & 910.263 & 2,31 \\
\hline 2008 & 7.247 .590 & 1.644 .584 & 4,40 \\
\hline
\end{tabular}

Fontes: DECEX (MICT) IBRAF-2010
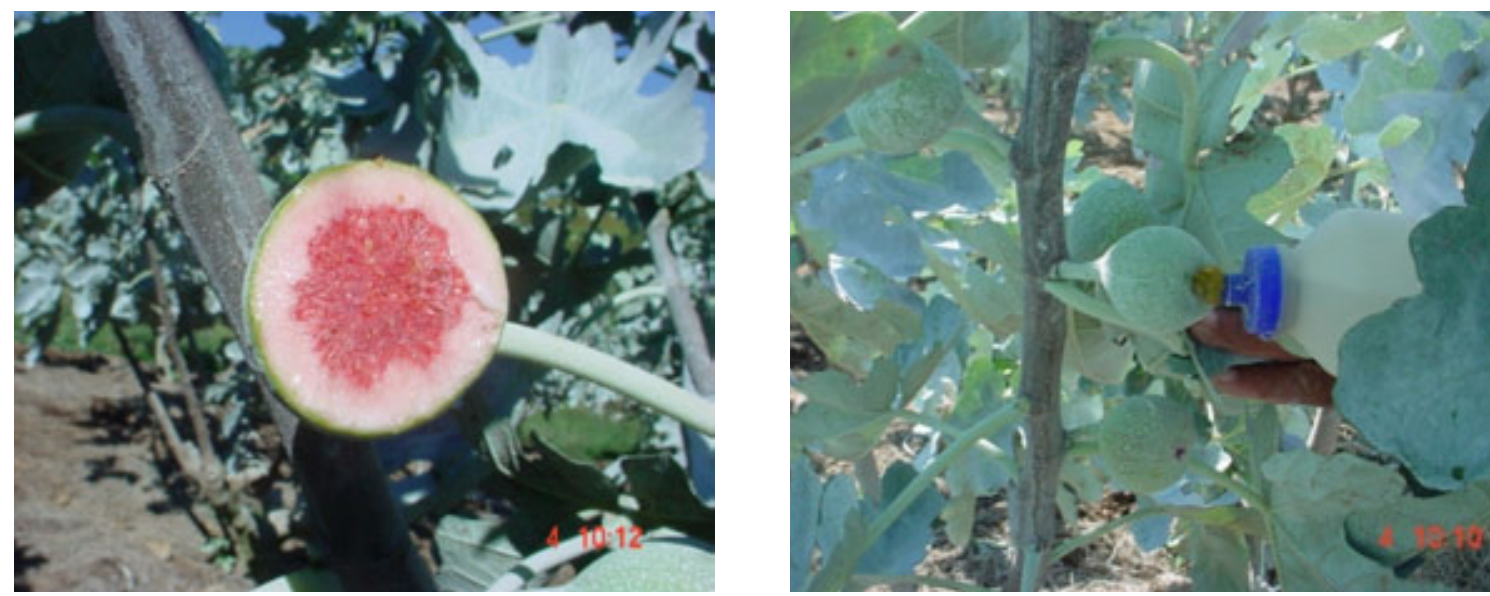

FIGURA 8 - Aplicação de Ethephon - ponto de aplicação e aplicação no ostíolo

\section{Produção Integrada}

As principais mudanças ocorridas no mundo, nas últimas duas ou três décadas, foram em todas as áreas de conhecimento e nos segmentos, principalmente, econômicos, sociais, éticos e governamentais, com ênfase nas questões ambientais. Isso tem determinado que as empresas busquem a aquisição e a manutenção de elevados níveis de competitividade em atendimento ao consumidor mais consciente e exigente. Essa competitividade está vinculada à manutenção e à ampliação de mercados que resultam da abertura da economia mundial, criação e unificação de mercados em blocos regionais, com consequente elevação da concorrência em níveis globais.

No final de 2000, por meio do Convênio Ministério da Agricultura, Pecuária e Abastecimento - MAPA, e Conselho de Desenvolvimento Científico e Tecnológico - CNPq, foram disponibilizados recursos para apoiar o desenvolvimento de projetos de Produção Integrada em 14 culturas, em nível nacio- nal. Uma das fruteiras contempladas foi a cultura da figueira, que está entre as principais frutas de clima temperado produzidas no Brasil.

Assim, o trabalho conjunto entre pesquisadores, extensionistas e produtores, durante os anos de 2002 a 2004, resultou na publicação das "NORMAS DA PRODUÇÃO INTEGRADA DE FIGO” (Instrução Normativa ${ }^{\circ} 2$, de 22 de fevereiro de 2005 -D.O. União 02 de março de 2005.

\section{ZAPRIONUS}

Durante a safra de figo de 1998/1999, na região de Valinho (SP), foi constata a presença de uma grande quantidade de pequenas moscas alimentando-se e fazendo posturas na região do ostíolo dos figos em início de maturação. Uma grande quantidade de larvas foi também observada dentro de alguns frutos, tornando-os impróprios para o consumo humano. A análise do material pelo Departamento de Biologia do Instituto de Biociências da Universidade de São 
Paulo, São Paulo (SP), confirmou que se tratava da espécie Zaprionus indianus Gupta, 1970 (Diptera: Drosophilidae), que teve o primeiro registro publicado (VILELA, 1999) sobre a ocorrência no continente americano, em exemplares observados em frutos de caqui, no município de Santa Isabel-SP, no dia 20 de março de 1999.

No início de 2000, esta praga causou muitos transtornos aos produtores, tanto na exportação como no mercado interno, o que levou à busca de solução para melhor convivência com o novo problema. Visto que o uso do agrotóxico não resolvia a questão, os produtores, através de pesquisadores e técnicos da extensão, foram buscar as alternativas para o controle desta praga. Assim, através da mudança do manejo cultural, como: limpeza dos pomares e seus arredores, mantiveram-se as plantas de figo e outras frutíferas isentas de frutas em estágio avançado de amadurecimento e danificadas por insetos ou pássaros, queimando ou enterrando qualquer tipo de vegetal (principalmente frutas e legumes) que pudessem entrar em estado de decomposição, pois poderiam constituir-se em focos de criação da mosca e não abandonar pomares de qualquer espécie com frutos maduros e desenvolver armadilhas atrativas com garrafas pet (MAIORANO, 2010).

\section{GOIABEIRA - Psidium guajava L.}

A goiabeira é planta originária do continente americano, sendo bastante amplo seu centro de origem (do México ao Peru e Brasil).

A expansão da espécie ocorreu em praticamente todas as regiões tropicais e subtropicais do globo terrestre, levadas primeiramente por navegadores espanhóis e portugueses.

Atualmente, alguns dos principais centros produtores são o Brasil, México, Índia, China, Paquistão e África do Sul, ou seja, países em desenvolvimento que carecem de recursos para um adequado programa de pesquisas científicas que possam propiciar um efetivo avanço tecnológico para a cultura da goiabeira.

No Brasil, com área de 15.048ha e produção de 297.377t (IBRAF, 2009), as pesquisas concentram-se nos principais estados produtores, ou seja: São Paulo (25\%), Pernambuco (25\%), Pará $(7 \%)$, Bahia (7\%) e Rio de Janeiro (6\%), especialmente realizadas nas Universidades, nos Centros de Pesquisa e por produtores e empresas públicas ou privadas.

A exploração comercial da goiabeira iniciou-se em fins da década de 1950, sob dois modelos distintos, ou seja: goiabas para mesa e goiabas para processamento industrial.

\section{Goiabas para mesa}

Em fins da década de 1950, iniciou-se o cultivo principalmente em localidades próximas aos grandes centros urbanos como São Paulo e Rio de Janeiro. Trabalhos realizados por produtores brasileiros de origem japonesa, como Tadao Ogawa e Sinishi Ogawa, propiciaram o desenvolvimento, não apenas de novas técnicas de cultivo, de propagação vegetativa (enxertia), mas também de novas cultivares. Mais tarde, com a exploração de goiabas de mesa em outras regiões, novas técnicas de produção assim como novas cultivares foram selecionadas.

Entre as cultivares de goiaba para mesa, devem-se destacar: Ogawa $n^{\circ} 1, n^{\circ} 2$ e $n^{\circ} 3$, Pedro Sato, ainda hoje muito cultivada, Sassoka de casca rugosa e Kumagai de polpa branca (Figura 9), base de exportação da goiaba brasileira.

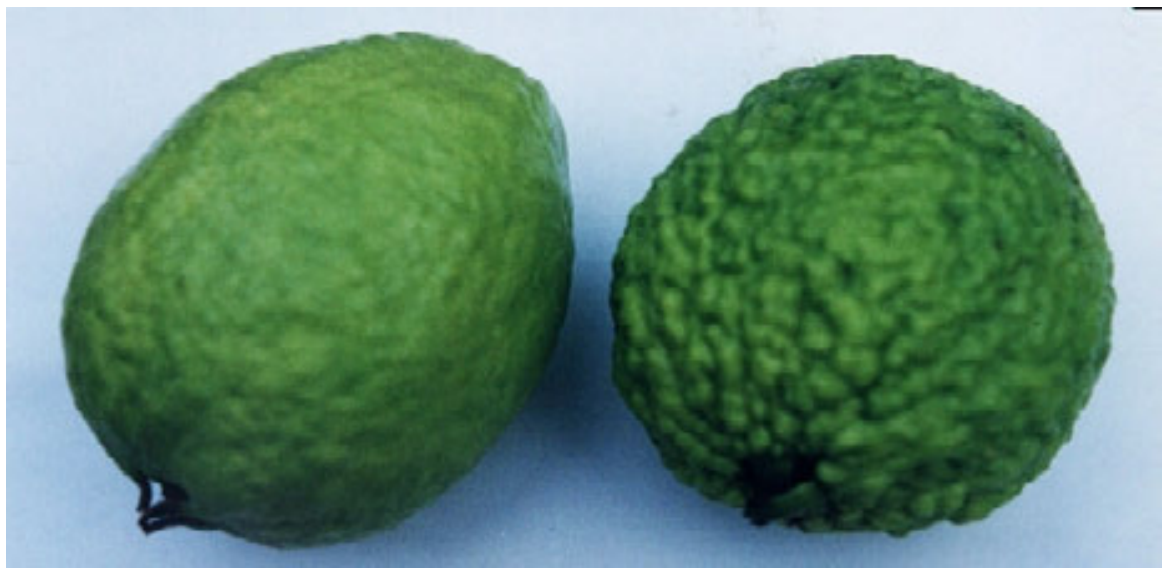

FIGURA 9 - Pedro Sato e Sassoka, importantes cultivares de goiaba de polpa vermelha 

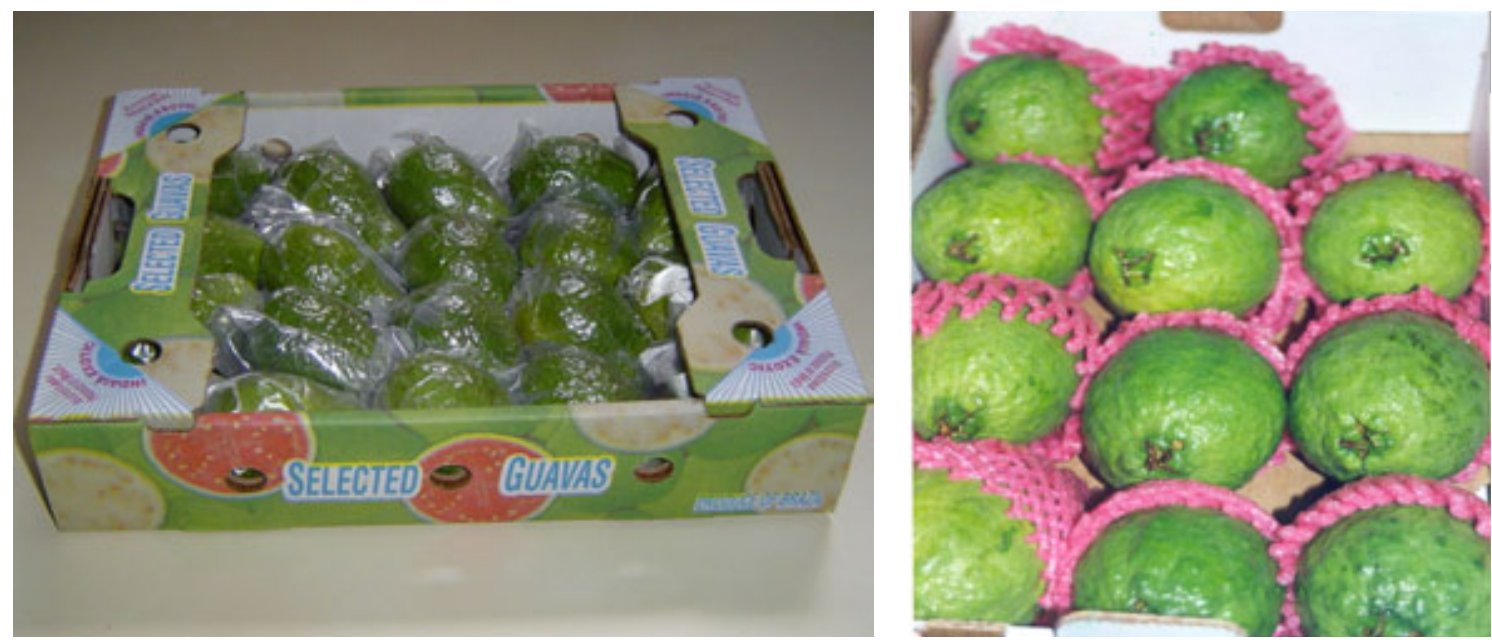

FIGURA 10 - Embalagens de goiaba, respectivamente, para exportação e mercado interno.

Entre as técnicas culturais devem ser destacadas: a propagação vegetativa por borbulhia, as técnicas de poda, que permitem a produção em qualquer época do ano, e o ensacamento dos frutos, que possibilita a produção de frutos sem resíduos de agrotóxicos.

Entre os trabalhos desenvolvidos nas instituições de ensino e pesquisa, devem-se ressaltar os realizados no Instituto Agronômico de Campinas, que conduziram a utilização de práticas culturais e fitossanitárias que atualmente permitem um efetivo controle da doença bacteriana causada pela Erwenia psidii sp., que afetou gravemente os goiabais paulistas no início dos anos 80.

Importantes pesquisas sobre a pós-colheita da goiaba foram realizadas na FCAV - UNESP/ Jaboticabal, ESALQ - USP e UNICAMP.

Essas pesquisas permitiram avanços nos procedimentos de colheita e embalagem dos frutos e a valorização da goiaba por seu valor nutritivo, destacando-se o teor de licopeno nas goiabas de polpa vermelha.

\section{Goiabas para processamento industrial}

A tão apreciada goiaba produzida desde os tempos remotos apenas despertou interesse comercial com o declínio da cultura do marmeleiro (anos 1950), ocasião em que, paulatinamente, substituiu a então famosa marmelada.

A goiabada, entretanto, já era produzida de forma artesanal nas fazendas, sendo os frutos maduros trazidos aos porões das "casas grandes", onde, em tachos de cobre, as escravas, após adicionar açúcar, levavam ao fogo até o adequado cozimento. Conservada em caixas de madeira, a goiabada era servida com queijo fresco (Romeu e Julieta), durante todo o ano, como fina sobremesa.

Foi na região de Jaboticabal que empresas alimentícias, como CICA(Monte Alto), ETTI e PEIXE (Taquaritinga), desenvolveram a produção em escala da goiabada, que em curto espaço de tempo se tornou o doce mais consumido no Brasil.

A produção de matéria-prima dessas indústrias era obtida de pomares implantados por sementes que se caracterizavam por uma grande variabilidade genética, plantas de grande porte, pequena utilização de tecnologia agrícola e relativamente baixa produtividade.

A inexistência de variedades abriu a possibilidade para o desenvolvimento de um programa de melhoramento genético da goiabeira, visando à obtenção de plantas com alta produção de frutos de qualidade para a elaboração de doces e polpas. 


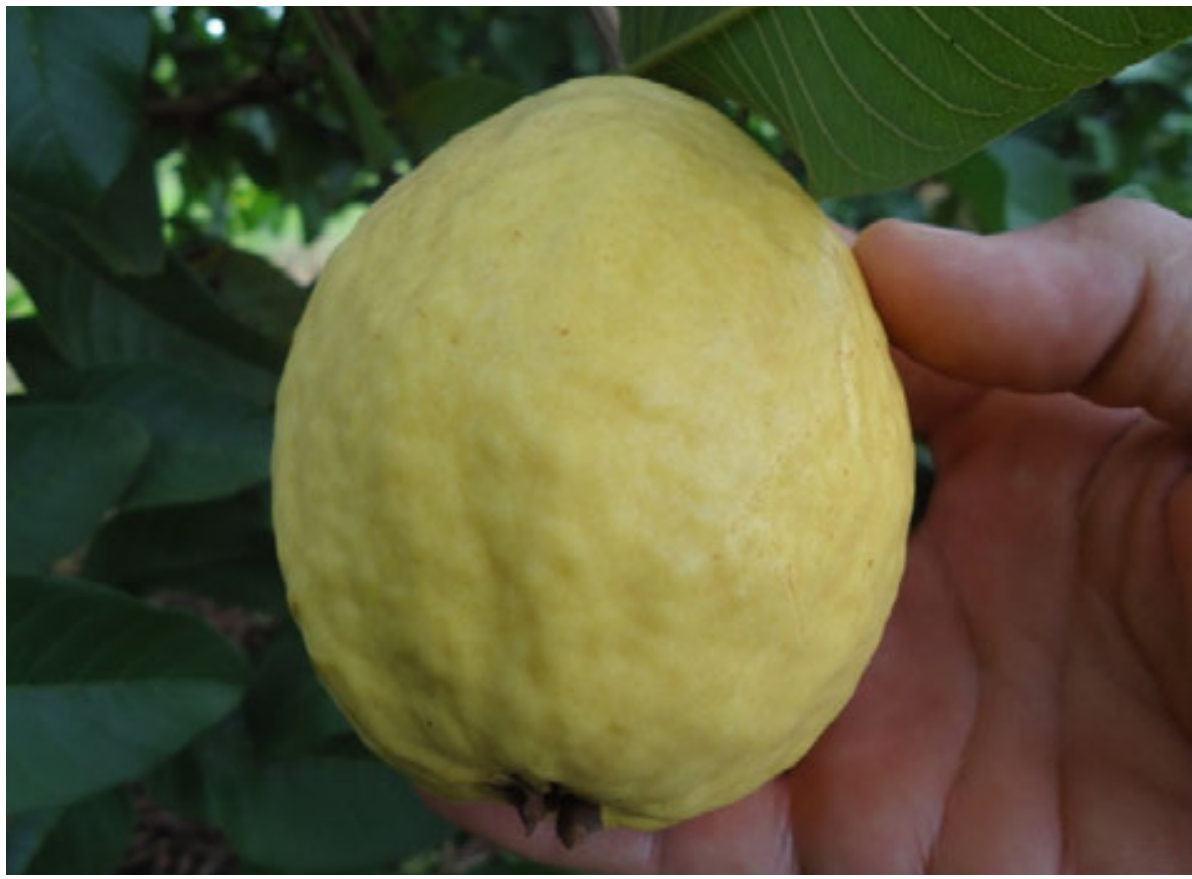

FIGURA 11 - Paluma, a principal cultivar de goiabas em uso no Brasil

O projeto realizado na FCAV - UNESP/ Jaboticabal, inicialmente (1976) utilizou a seleção massal, de material genético trazido de diferentes regiões produtoras.

As análises, durante dez anos, das plantas em estudo, resultaram no lançamento das cultivares Paluma (Figura 11) e Rica. Mais tarde, em 1985, projetos com cruzamento controlado entre as melhores plantas da área experimental possibilitaram selecionar a cultivar Século XXI (Figura 12).

Atualmente, cerca de $70 \%$ das goiabeiras cultivadas no Brasil, com o objetivo de produção de frutos para processamento industrial, são da cultivar Paluma.

A Século XXI vem expandindo-se rapidamente, sendo seus frutos também muito apreciados como goiaba de mesa.

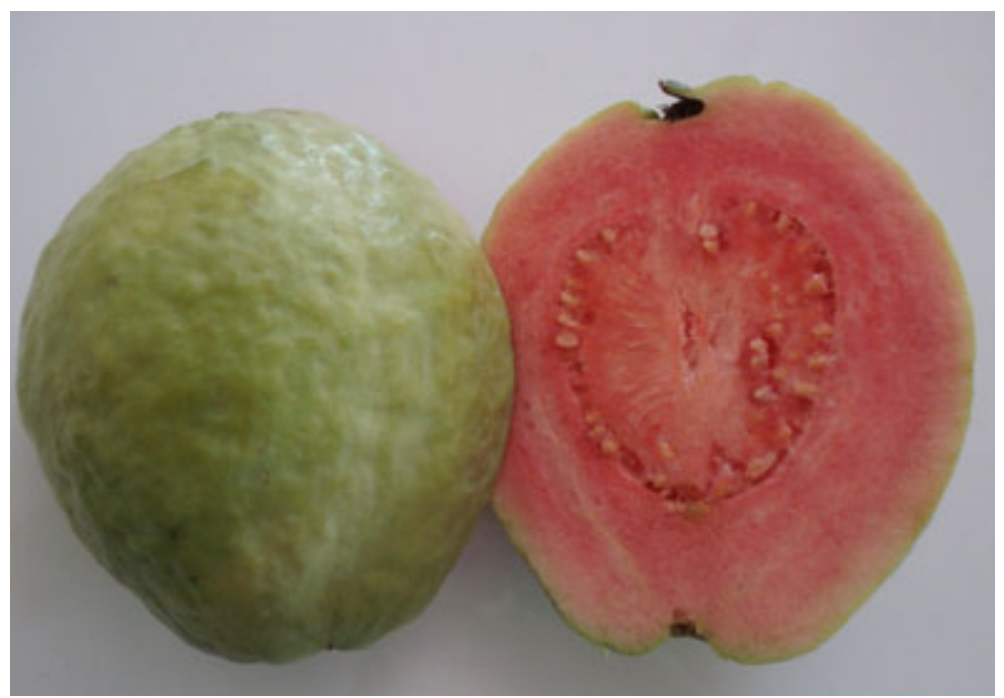

Figura 12 - Cv. Século XXI, apreciada também como goiaba de mesa. 
Como a formação de mudas de goiabeira por sementes não possibilitava a fixação de variedades, devido à grande variabilidade genética, e a implantação de pomares para a produção de frutos destinados à industrialização por enxertia era inviável (devido ao alto custo das mudas), foi necessário desenvolver um processo economicamente viável para a propagação de novos materiais geneticamente superiores.

Com esse objetivo, na FCAV-UNESP/ Jaboticabal (1985), também sob a responsabilidade do Prof. Dr. Fernando Mendes Pereira, foi conduzido um projeto de propagação vegetativa da goiabeira através da estaquia herbácea (Figuras 13 e 14).

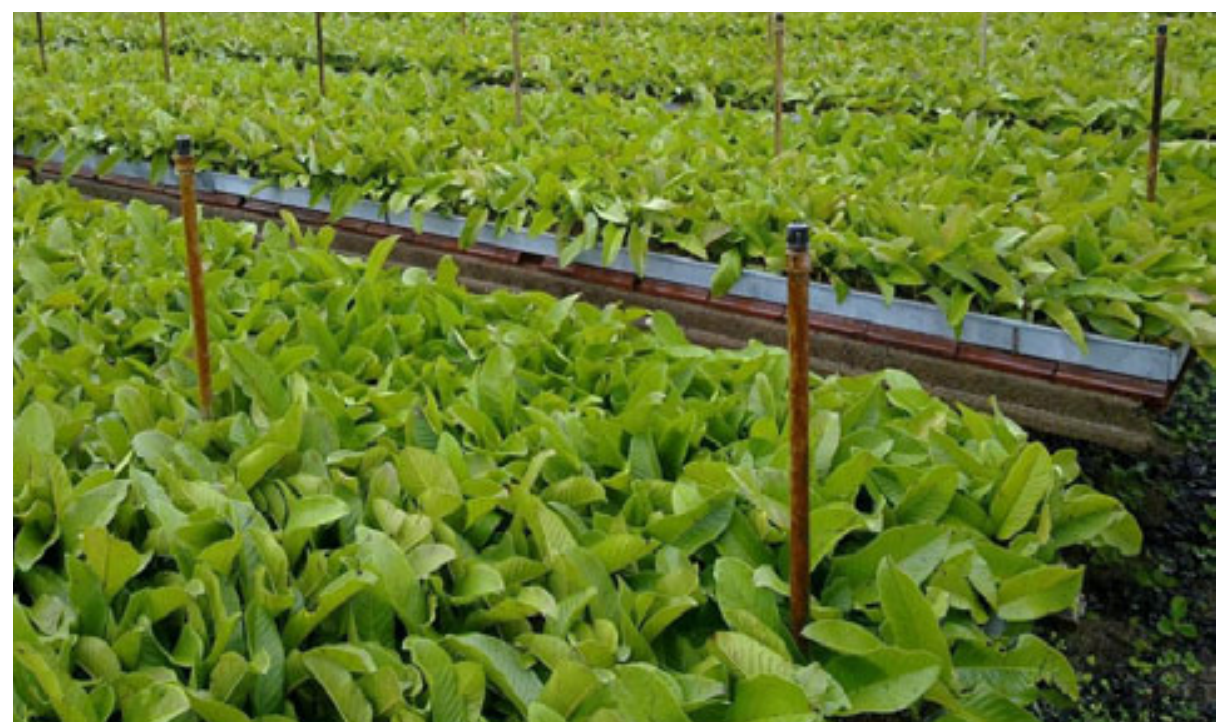

FIGURA 13 - Câmara de nebulização, estacas enfolhadas

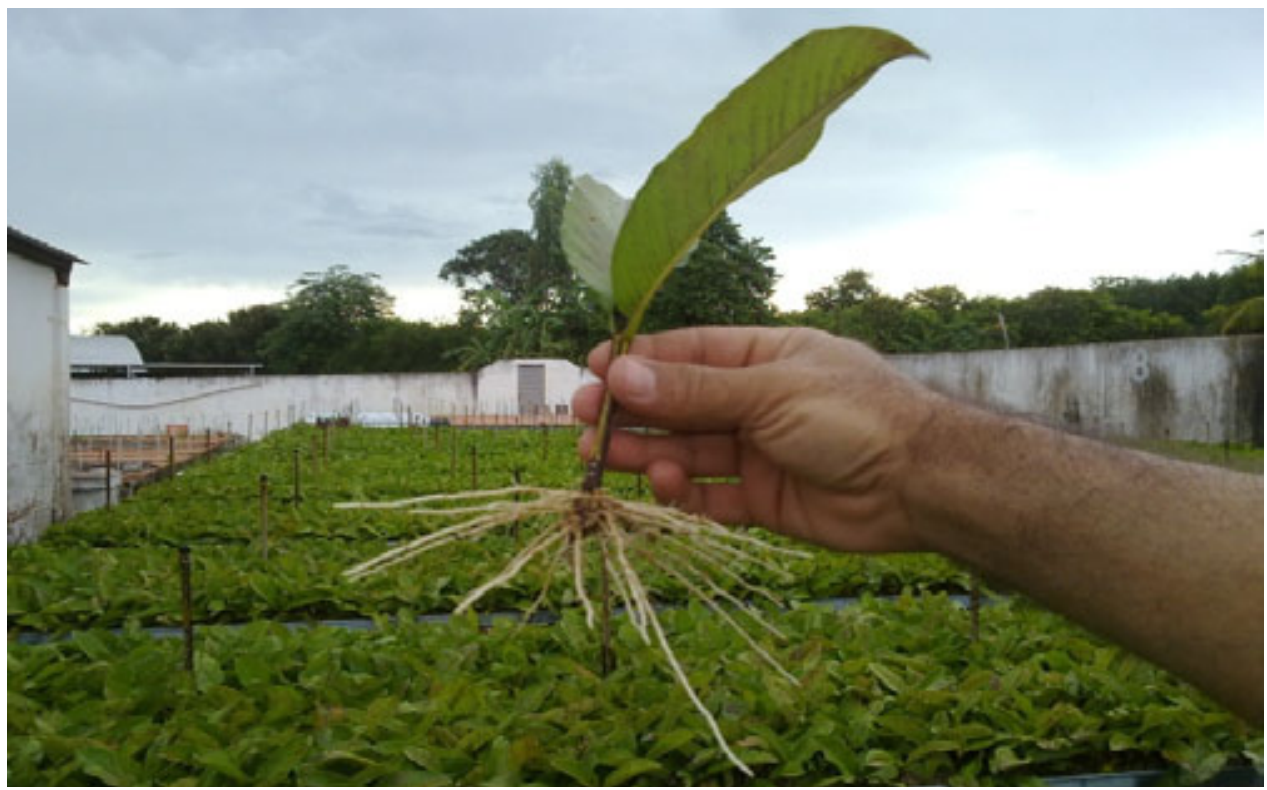

FIGURA 14 - Estaca enraizada adequada para o transplante

Com grande esforço, foi possível estabelecer a tecnologia básica para a produção de mudas de goiabeira por estaquia herbácea, que resultou na instalação de viveiros em muitos estados brasileiros, responsáveis pela produção de um número superior a 3 milhões de mudas (Figura 15). 

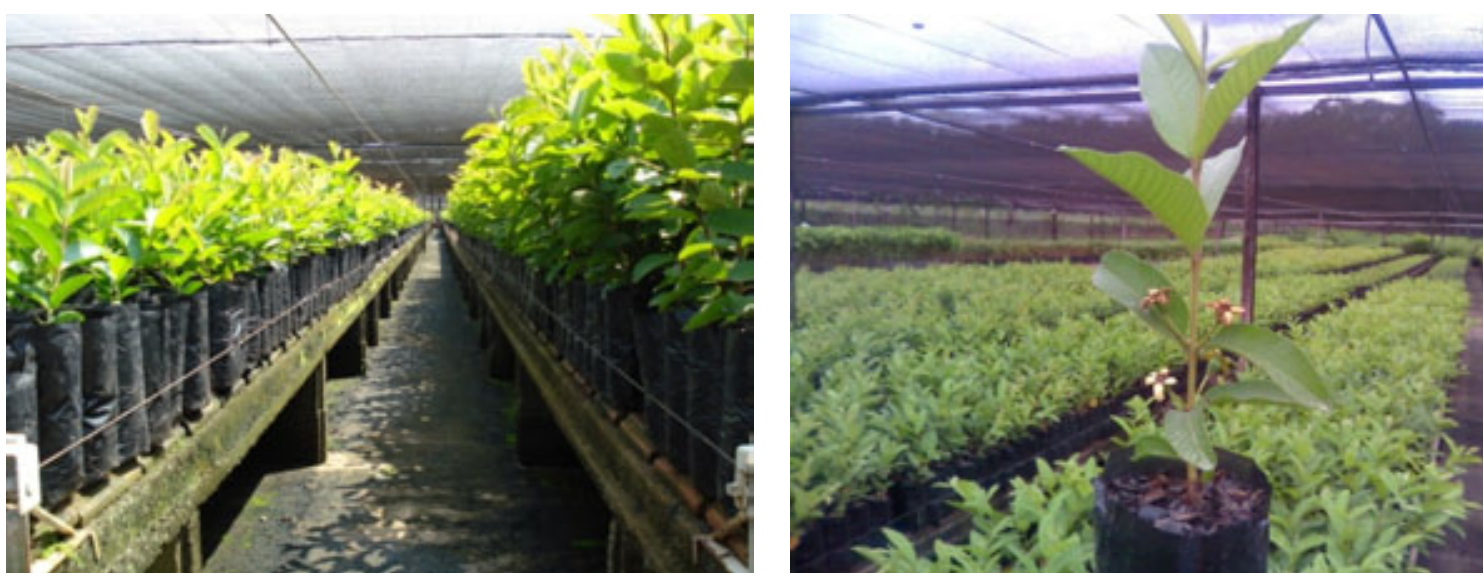

FIGURA 15 - Mudas de goiabeira Paluma prontas para o plantio definitivo.

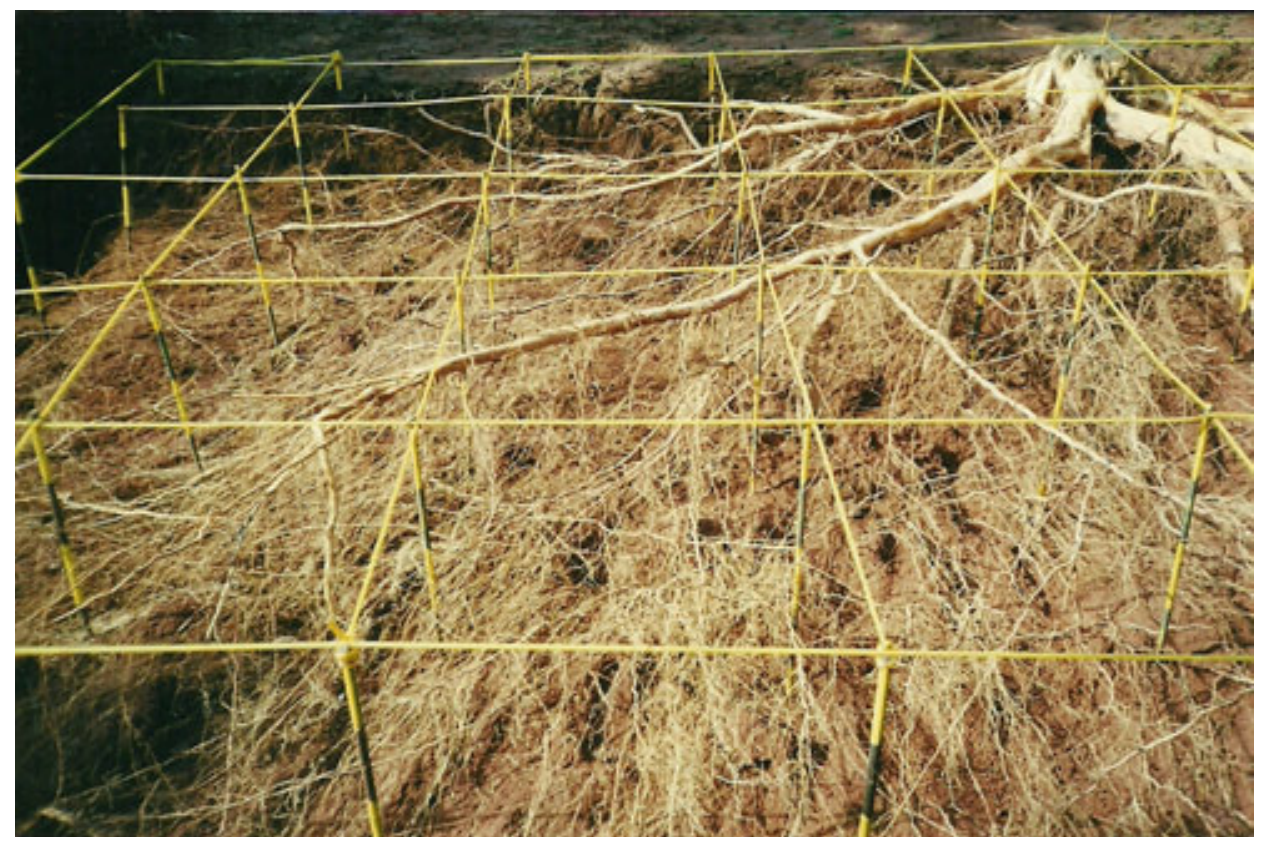

Figura 16 - Enraizamento de goiabeiras propagadas por estaquia herbácea dez anos após o plantio no campo.

O desenvolvimento de novas cultivares, com novas tecnologias de propagação, exigiu novos conhecimentos sobre técnicas culturais e fitossanitárias que propiciassem maiores resultados econômicos aos produtores de goiabas para a industrialização.

Assim sendo, muitas pesquisas foram realizadas, visando a conhecer melhores e mais adequados tratos culturais e fitossanitários a serem empregados nos pomares.

Entre os diversos trabalhos realizados, merecem destaques aqueles que estabeleceram critérios para a realização das podas drásticas que permitiram melhor condução das plantas e produções durante praticamente todo o ano e pesquisas sobre nutrição e adubação da goiabeira que resultaram na adequada adubação dos pomares, com evidentes ganhos de produtividade. Grande parte destas pesquisas foi realizada por professores e alunos da FCAV-UNESP/ Jaboticabal, sempre com o apoio das empresas processadoras de goiabas, especialmente HERO e CICA. 


\section{REFERÊNCIAS}

BETTIOL NETO, J.E. Conservação de pólen de anonas comerciais. Dissertação (Mestrado), 2008, 78 f. Instituto Agronômico de Campinas, Campinas, 2008.

CASTRO, A. G. Cultura do caqui. A lavoura, 872 (3-4); p. 40. 1969.

CORREA, L. S.; BOLIANI, A. C. (Ed) Cultura da Figueira: do plantio à comercialização. SIMPÓSIO BRASILEIRO SOBRE A CULTURA DA FIGUEIRA, 1., 1999, Ilha Solteira.

KAVATI, R. O cultivo de atemoia. In: DONADIO, L.C. Fruticultura Tropical, FUNEP, Jaboticabal, 1992. p.39-70.

KAVATI, R. Efeito de época de poda na produção tardia e fenologia de atemoia (Annona cherimola Mill. X Annona squamosa L.), cv. Gefner. Dissertação (Mestrado), 1998, 105 f. Faculdade de Ciências Agrárias e Veterinárias, Universidade Estadual Paulista, Jaboticabal, 1998.

MAIORANO, J. A. A história e a origem da figueira. In: História da Fruticultura Paulista. Sociedade Brasileira de Fruticultura, p. 174-184. 2010.

MANICA, I.; ICUMA, I.M.; JUNQUEIRA, K.P.; OLIVEIRA, M.A.S.; CUNHA, M.M.; OLIVEIRA Jr., M.E.; JUNQUEIRA, N.T.V.; ALVES, R.T. Frutas Anonáceas: Ata ou Pinha, Atemoia, Cherimólia e Graviola - Tecnologia de Produção, Pós-colheita, Mercado. Cinco Continentes, Porto Alegre, 2003. 596p.

MARTINEZ JÚNIOR, M. Estudos dos efeitos de diferentes épocas de poda, associadas à aplicação de paraquat e /ou calciocianamida, na antecipação da colheita de goiabas para utilização industrial. 1979. 75p. Monografia (Trabalho de Graduação em Agronomia) - Faculdade de Ciências Agrárias e Veterinárias, Universidades Estadual Paulista, Jaboticabal, 1979).

MARTINEZ JÚNIOR, M.; PEREIRA, F. M. Respostas da goiabeira a diferentes quantidades de N, P e K. In: CONGRESSO BRASILEIRO DE FRUTICULTURA 8., 1986. BRASILIA. Anais... Brasília: SBF, 1986. p. 293-296.
MARTINS, F. P.; PEREIRA, F. M. A cultura do caquizeiro. Jaboticabal, FUNEP, 71p., 1989

MELO, M.R. Polinização natural e artificial da cherimoia e atemoia no Estado de São Paulo. Dissertação (Mestrado), 2001, 60 f. Instituto Agronômico de Campinas, Campinas, 2001.

NATALE, W. Adubação, nutrição e calagem da goiabeira. In: NATALE et al. (Ed). Cultura da goiaba: do plantio a comercialização: Jaboticabal: FUNEP, 2009, p. 357-280.

NATALE, W., COUTINHO, E. L. M.; BOARETTI, A. E., PEREIRA, F. M.; MODENESE, S. H. Goiabeira: calagem e adubação. Jaboticabal: Funep, 1996. 22p.

OJIMA. M. e Outros. Fruticultura de clima temperado no Estado de São Paulo. Diagnóstico da situação econômica e cultural e atividades de pesquisa no IAC. Campinas. Boletim Técnico, 89, 1989. 72p.

PELINSON, G.L.B. Efeito e técnicas visando à melhoria da qualidade e produção de pinha (Annona squamosa L.) no período de entressafra. Dissertação (Mestrado), 2003, 94f. Universidade Estadual Paulista, Câmpus de Ilha Solteira, Ilha Solteira, 2003.

PEREIRA, F. M. Efeitos dos reguladores de crescimento ethephon e giberilina, sobre a maturação de frutos da figueira (Ficus carica $\mathbf{L}$.) variedade Roxo de Valinhos. 1979. 91p. Tese de Livre-Docência - Faculdade de Ciências Agrárias e Veterinárias, Universidade Estadual Paulista, Jaboticabal.

PEREIRA, F. M. Rica e Paluma: novas cultivares de goiabeira. In: CONGRESSO BRASILEIRO DE FRUTICULTURA, 7., 1984, Florianópolis. Anais... Florianópolis: SBF, 1986. p. 524-528

PEREIRA, F. M.; OLIOLI, A. A. P.; BANZATTO, D. A. Enraizamento de diferentes tipos de estacas enfolhadas de goiabeira (Psidium guajava L.) em câmaras de nebulização. Científica, Jaboticabal, v. 11, n.2, p.239-244, 1983. 
PEREIRA, M.J.B. Biologia, exigência térmicas e inimigos naturais da broca-da-polpa das anonáceas Cerconota anonella (Sepp, 1830) (Lepidóptera:Ocecophoridae). Tese (Doutorado), 2001. Escola Superior de Agricultura "Luiz de Queiroz", Piracicaba, 2001.

PIRES, M. O Pomo da riqueza: história do figo roxo de Valinhos, 1970. 96p.

RIGITANO, O. A figueira cultivada no Estado de São Paulo. 1955. 59f. Tese (Doutorado). Escola Superior de Agronomia "Luis de Queiroz", Universidade de São Paulo, Piracicaba, 1955.

SÃO JOSÉ, A.R.; SOUZA, I.V.B.; MORAIS, O.M.M.; REBOUÇAS, T.N.H. Anonáceas Produção e Mercado. UESB, Vitória da Conquista, 1997. 308p. SAVAZAKI, E.T. Efeito do ácido indolbutirico no enraizamento de estacas de três cultivares de atemoia (Annona cherimola Mill. X Annona squamosa L.) e formação de muda. Dissertação (Mestrado), 2000. Faculdade de Ciências Agrárias, Universidade Estadual Paulista, Botucatu, 2000.
SCALOPPI Jr., E.J. Clonagem de quarto espécies de Annonaceae (Annona glabra L., Annona montana Macfad, Rollinia emarginata e Rollinia mucosa Baill.) potenciais como porta-enxertos. Dissertação (Mestrado), 2003. Faculdade de Ciências Agrárias e Veterinárias, Universidade Estadual Paulista, Jaboticabal, 2003.

SCALOPPI Jr., E.J. Propagação de espécies de Annonas com estacas caulinares. Tese (Doutorado), 2007. Faculdade de Ciências Agrárias e Veterinárias, Universidade Estadual Paulista, Jaboticabal, 2007. SOUSA. J. S. I. Tópicos sobre a cultura do caquizeiro. I $^{\mathrm{o}}$ Anuário do Fórum Paulista de Fruticultura. s/d.

TOKUNAGA, T. A cultura de atemoia. CATI Boletim Técnico n ${ }^{\circ}$ 233. Campinas, 2000. 80p.

VAZ, H. Cultura do Kakizeiro. Revista da Agricultura, 1 (4). p. 20-22. 1925.

WATANABE, H.S. Comercialização de anonáceas na CEAGESP e Sistema PROHORT da CONAB. Informativo Anonas Brasil nº4, 2011, no prelo. 